\title{
Applied Ethics and eHealth: Principles, Identity, and RFID
}

\author{
Diane Whitehouse $^{1}$ and Penny Duquenoy ${ }^{2}$ \\ ${ }^{1}$ The Castlegate Consultancy, 27 Castlegate, Malton, \\ North Yorkshire, England YO17 7DP, UK \\ ${ }^{2}$ Middlesex University, UK \\ diane.whitehouse@thecastlegateconsultancy.com, \\ P.Duquenoy@mdx.ac.uk
}

\begin{abstract}
The social and ethical implications of contemporary technologies are becoming an issue of steadily growing importance. This paper offers an overview in terms of identity and the field of ethics, and explores how these apply to eHealth in both theory and practice. The paper selects a specific circumstance in which these ethical issues can be explored. It focuses particularly on radiofrequency identifiers (RFID). It ends by discussing ethical issues more generally, and the practice of ethical consideration.
\end{abstract}

Keywords: Applied principles, consent, convergence, eHealth, ethics, health, identity, identity management, privacy, RFID, security.

\section{Introduction}

The growing range of information and communication technologies (ICT) that is available, and its diverse uses in different capacities, whether personal, professional, informal or formal, raises a number of interesting - indeed challenging - questions about human identity. As the June 2008 conference organised by the Centre for Ethics and Technology, Delft, Netherlands, suggested:

Access, rights, responsibilities, benefits, burdens and risks are [now] apportioned on the basis of identities of individuals. These identities are formed on the basis of personal data collected and stored and manipulated in databases. This raises ethical questions, such as obvious privacy issues, but also a host of identity related moral questions concerning (the consequences of) erroneous classifications and the limits of our capacity for self-presentation and self definition.

http://www.ethicsandtechnology.eu/ Accessed 16 June, 2008

The aim of this paper is to demonstrate the tight relationship between ethics and current technologies against the background of the eHealth domain. The paper is based on contributions to two International Federation for Information Processing (IFIP) summer schools, held in 2007 and 2008. These concentrated on issues relating to ethics, identity, and identity management in the Information Society. eHealth, as a particular case study, raises a number of issues relating to identity and therefore provides a useful context for investigation. 
To introduce the key issues of ethical debate, the paper progresses as follows. It outlines the relationship between identity, health, eHealth, and ethical issues. It describes the development of eHealth, particularly in Europe. A brief introduction to ethics sets the stage for a general discussion on eHealth and ethics. An overview of the ethical principles that inform the healthcare sector comes next. These principles are applied to the healthcare setting. Ethical dilemmas that surround a particular technology used in the eHealth area are introduced - radio frequency identifiers (RFID). The issues at stake relate principally to privacy, security, and consent. Finally, a broad set of conclusions are formulated.

The context, evidence and examples that are described are generally those of the European scene. This is the authors' location and tends to be their area of particular interest. Clearly, however, these issues are not uniquely European, they are global. In this sense, we fully recognise the achievements of e.g. the World Health Organisation and the World Bank in terms of eHealth policy development and implementation. In a growingly international ('flat') world, how we handle the provision of healthcare for the benefit of peoples in all parts of the globe may be about to change substantially [39].

\section{Identity, Health, and eHealth}

Identity relates to people's personal conceptions of themselves and the different ways in which others view them (as a patient, for example, or conversely as a doctor/expert). Identity is fundamental to the carrying-out of healthcare: it enables the identification of types of disease which citizens or patients experience, and their degree of wellbeing; it can help define the stage in the lifecycle at which patients are, and the disease grouping into which they fit. These characteristics may even enable eventually more effective triage, the process of "the assignment of degrees of urgency to wounds or illnesses to decide the order of treatment of a large number of patients or casualties" [28]. Today, technology-based equivalents and mechanisms to support these processes can include the out-of-hours telephone, email, and Web-based facilities available in some countries (e.g., the National Health Service (NHS) Direct (NHS Direct) service in England).

Thus, identity and identification can influence the appropriate form of treatment given to citizens/patients. In this broader sense, identity plays a role in organisational management in terms of who gets treatment, who delivers it, and how healthcare overall is managed. The traditional, and changing, power relations among the various participants in the health arena also influence these choices.

eHealth today forces a high degree of focus on identity, because technology intervenes increasingly in the various processes involved in the understanding of and provision of healthcare. ICT mediates between the practitioner and the patient, and may have considerable influence on organisational practice. Increasing convergence is taking place, both in terms of the technologies associated with health/eHealth practice and in relation to the diminishing degrees of separation between difference areas of health activity: whether the wellness industry, primary care, secondary care, clinical research, rehabilitation, care, and pharmaceutical practice.

Hence, what needs to occur is the correct identification of the patient; the specific health professional(s) involved; and the particular institution. Sound and secure methods of identifying human beings are needed so that appropriate analysis, diagnosis, 
treatment, and follow-up can be given correctly and confidentially to the individuals concerned. Appropriate files need to be linked and integrated [20] and data management practices implemented. This maintenance of correct data and identification methods is fundamental to the ethical practice of healthcare (discussed in sections 4.1 and 4.2).

Good data management, however, is not only to be considered in respect of ethics and identity. Other ethical issues that are pertinent to eHealth are associated with the personalisation and the degree of intimacy of the particular technology. Examples include technology implants; genetic analysis; and the uses to be made of health data [24,33,37].

Clearly Radio Frequency Identification (RFID) offers a possible solution to identifying people, products, and services throughout the health sector. However, it is also evident that there are social and ethical concerns which might mitigate or at least modify its widespread use $[2,17,25]$.

\section{3 eHealth - Definition and Background}

What precisely is eHealth? A number of definitions are available in the academic literature and in policy-related materials $[6,8,14,26,27]$. In this context, we have chosen to focus on one of the more pragmatic and applied definitions. This well-known description was included in the text of the eHealth action plan [6, p4]:

[eHealth] describes the application of information and communications technologies across the whole range of functions that affect the health sector.

eHealth has alternatively been referred to as medical informatics or medical information systems, clinical informatics or clinical information systems, health informatics or health information systems, or information and communication technologies for health [12].

Historically, eHealth constitutes a journey with many milestones. ICT for health has been developing for over four decades - in Europe, for two. In the European Union, in the late 1980s, the early foundations of eHealth were laid; pilot studies were co-financed by the small number of countries which was composed of the originating members of the second stage of the European Union. From the 12 states at that era, the Union has now grown to 27 members. From an initial funding of €20 million in 1988, the investment in this particular domain of research and development expanded tenfold in the Sixth Framework Programme. The Commission is now co-financing the Seventh Framework Programme that extends throughout the period, 2007 to 2013. The amount of financing provided by the Commission dedicated to eHealth in this Framework Programme is expected to be well over €200 million. Its emphasis is on fields of research activity such as personalised health (health information systems that support healthcare for individuals), patient safety, and work on the model of the "virtual physiological human" (the bringing together of very large databases that can merge clinical, genomic, and environmental data so as to predict and describe the health status of individuals much more effectively).

However, it is not only research in eHealth that is of importance. eHealth has become an area for strong policy development with the formulation of a seven-year plan for policy convergence [6]. 2008 has been a key year for eHealth in Europe, in this sense. In 
the context of patient mobility, cross-border health services, and eHealth interoperability, a Proposal for a Directive and a Recommendation have already been adopted [9,11]. A policy document on telemedicine was published in the same year [10].

There is much current emphasis on the actual deployment and application of eHealth. eHealth is perceived as a key enabler of good healthcare, and a means of reinforcing the Union's common values and goals for its health systems. Two-thirds of the Member States believe that their health policy priorities can be supported by eHealth. Not only does every European Member State now possess its own eHealth road map or action plan, but all the States are now building their own initiatives to apply eHealth systems, services, and applications. While there are many commonalities among the 27 States, there is, nevertheless, considerable disparity among them with regard to their stages of innovation and how they are putting eHealth into practice [16]. This 2007 overview shows that the principal, common eHealth services in European countries all have relevance for ethical concerns such as the quality of care and the importance of access to care of the patient/citizen. Of the six eHealth domains which most Member States are introducing, building, and using, the three technical areas are infrastructure, electronic health records or cards, and interoperability (Ibid, p13-15).

On two recent occasions, the Member States have committed themselves to work together on eHealth ${ }^{1}$. This engagement is paralleled by the practical developments of the European Commission's Competitiveness and Innovation Framework Programme (CIP) Information and Communication Technologies Policy Support Programme (PSP) (also known as the CIP PSP). This scheme supports the practical advance and integration of information and communication technologies use in their public sector domains among the Member States. In eHealth, the ministries of health, eHealth competence centres, and industry in 12 Member States focus on electronic health data (health records/medication records or "patient summaries") and ePrescribing. ${ }^{2}$

Finally, European and international industries are paying a renewed interest in the eHealth market. Many elements of the relevant industries are endeavouring to work together on a number of eHealth-related initiatives: one example is Continua Health Alliance ${ }^{3}$. In late 2007, the European Commission also launched a platform known as the Lead Market Initiative. This initiative emphasises the notion of the public sector as a driver of technological innovation and potential industrial growth - eHealth is one of the six domains to which attention is paid [8].

What next for eHealth in Europe as a whole is fast becoming one of Europe's biggest challenges.

\section{Ethics and Its Application}

Ethics constitutes a branch of moral philosophy, of which there are several schools of thought and action and a host of ethical theories. The consideration of ethics and ethical theory in relation to human behaviour is known as normative ethics, in contrast to

\footnotetext{
${ }^{1}$ See the conference declarations of two high-level (Ministerial) conferences in 2007 and 2008: http://ec.europa.eu/health-eu/news/ehealth/ehealth2007_en.htm and http://www.ehealth2008. si/ Accessed 8 January 2009.

${ }^{2}$ See http://www.epsos.eu/

${ }^{3}$ See http://www.continuaalliance.org/home/
} 
more abstract discussions on morality (i.e. meta-ethics). In the context of this paper, we are interested in normative ethics which is the practical application of ethics. In recent years, different ethical theories have been used to assess the ethical implications of ICT. Two of the most common theories used are Kantian ethics and utilitarian ethics (otherwise known as consequentialism).

Briefly summarised, Kant argues that human will motivates moral action, but that the will can only motivate itself from a rational foundation [21]. Accordingly, rationality implies autonomy (i.e. self-determination) and rational argument dictates that all human beings must be equal. These positions give rise to two propositions: to treat humanity always as an end in itself and never as a means to an end; and to act only on those principles (maxims) which at the same time one would desire to be a universal law. Kant specified: "Act only on that maxim which you can at the same time will to be a universal law" [21, p421].

Utilitarian ethics is located in the domain of 'consequentialist' ethics where the principles of moral actions are considered as being based on their consequences. The principle of utility ('utility principle') is that right actions bring the greatest happiness (determined as being either of the highest value or of the least harm) to the greatest number of people. One of the difficulties with this theory is that the consequences of actions cannot be predicted.

Ethical theories are useful as a point of departure to enable people to make appropriate choices and to act accordingly. They provide people with a form of toolkit that can enable them, at any moment in time and in any specific context - complete with its own criteria and constraints - to understand the particular moral position taken and the reasoning which underpins a specific moral choice.

These two theories have led to two distinct positions. In the first, there is a consideration of human autonomy and respect for others; in the second, a basis for deciding (and assessing) a course of action focused on the greatest benefit. In the following section, we consider principles that have been derived from these essential 'goods' and which have been applied to the practice of medicine, the field of health and, more recently, the combined fields of eHealth (i.e., medicine or health and ICT). The more applied the field, the more the ethical questions leap out and demand answers. The technologies involved add yet at least another layer of complexity to the issues involved.

\section{1 eHealth and Ethics}

Identity is an increasingly important issue for many fields of public sector services. In just one of these sectors - eHealth, a growing number of challenges relating relate to identity and identity management. It is always useful to view a hypothetical issue within an ethical domain in terms of practical examples. eHealth provides a realistic illustration of a number of ethical questions.

Ethics is fundamental to all fields of human concern. Issues relating to privacy, confidentiality, informed consent, and so on, can be seen as intrinsic to the health sector. They affect people often when they are at their most vulnerable. The health sector - and eHealth as a support mechanism that is implicitly part of it - can be considered as being based fundamentally on ethical notions; it is replete with ethical dilemmas. 
eHealth is of particular interest and preoccupation not only because it provides a means of supporting people's health (and health issues are based on moral or ethical imperatives), but also because of the questions that surround the technologies that are increasingly associated with healthcare and care provision.

A popular ethical framework that underpins the field of biomedical ethics [3] was first proposed some 20 years ago in 1989. The framework is described as a "set of mid-level principles mediating between high-level moral theory and low-level common morality" [19]. The four basic principles laid out are of non-malfeasance; beneficence; a respect for autonomy; and justice and equity. These four are described below:

\section{- Non-malfeasance}

Non-malfeasance means, of course, to 'do no harm' or primum non nocere - which lies at the very basis of all medical care. Aspects of non-harm may relate to increasing the quality of healthcare, and reducing its risk (hence, quality and safety).

\section{- Beneficence}

Beneficence means promoting wellbeing, increasing its level of safety (rather than just reducing risk), and protecting people. It is a more pro-active approach to healthcare. It too can be said to concentrate on aspects that relate to quality and safety.

\section{- $\quad$ Respect for autonomy}

Autonomy may relate to that of the health professional or to that of the particular citizen/patient whose health is at stake. It seems to have a relationship to the potential access to healthcare; as does the principle of justice and equity which follows.

- $\quad$ Principle(s) of justicelequity

These access-related principles have been especially strong in healthcare provision and management in Europe over the past sixty-year period.

These four notions are clearly of importance. Their implications are explored in detail in [12]. They match closely the ethical concepts of the two theories - Kantian and utilitarian - discussed in section 4. To do no harm and to promote wellbeing correspond to the notion of least harm or the greatest happiness (the utility principle). Respect for autonomy and principles of justice/equity relate to the theories of Kant.

An adaptation of unpublished work developed in [30] enables us to focus on some of the notions implicit in these four ethical principles, and to understand at the same time that there are further issues which require our attention, matters which relate to the economy and sustainability of health and healthcare.

With eHealth, the overall aim would be to create a balance of access ('A'), quality ('Q'), and economy (effectiveness and/or efficiency) ('E') ('AQE') in the particular health system or service. However, is the AQE relationship really an equilateral triangle? Or do its dimensions change at different points of time and in diverse circumstances? What happens when one adds the notions of provision and continuity (which may also affect quality), and safety (associated with quality or, indeed, with security) to the mix? Economy is surely closely related to principles of both the greatest good and at the same time respect for autonomy. Conceptually, are Kantian and utilitarian principles opposites or is a merger of the two possible (cf. implicitly [22])? Certainly, the economic aspects and the business models that underpin eHealth are likely to take 
on a far higher prominence than was previously the case [8]. However, so too, under conditions of economic crisis, may altruism, benevolence, and voluntarism.

The abundant late $20^{\text {th }}$ century distribution of labour as support to healthcare may well have to pass on, away, and down - over the next decades - from specialists to generalists and, indeed, to citizens and patients themselves (e.g. [39,40]. The economics and re-organisation of healthcare may require serious consideration.

\subsection{Applied Principles in eHealth}

High-level principles can be brought to bear on specific areas of application. Codes of ethics provide the ethical foundation for many organisations, particularly professional bodies. The ICT industry encompasses a range of disciplines that include electronic engineering, computer science, and information management. The ethical principles of these professions fall usually into groupings that state that they protect the public interest, uphold the standards of the specific profession, promote knowledge transfer, and require a commitment to personal integrity. Of direct relevance in this case are the "rules of conduct" for Health Informatics Professionals drawn up in the United Kingdom under the auspices of the Health Informatics Committee of the British Computer Society. They recognise the role played by ICT in the field of medicine [22].

The complexity of modern society and communities of work mean that the ethics of specific occupations (e.g. their codes of ethics, behaviour, or practice) need to be given careful consideration when each meet in realms of collaborative or cooperative practice. In eHealth, a wide range of different occupations and professions may converge e.g. clinicians, researchers, insurers, and pharmacists. Similar tensions may face small organisations (or scopes) when merged with larger ones.

The fundamental ethical principles laid down by [22], follow those outlined in section 4.1. They are the: Principle of Autonomy; Principle of Equality and Justice; Principle of Beneficence; Principle of Non-Malfeasance; and the Principle of Impossibility. (This last principle relates to the assumption that it must be possible to meet the rights and duties that are expressed by the previous three statements.) These principles are transposed into concrete and practical uses that are aligned with the responsibilities of Health Informatics Professionals. The professional has "a duty to ensure that appropriate measures are in place that may reasonably be expected to safeguard: The security of electronic records; The integrity of electronic records; The material quality of electronic records; The usability of electronic records; The accessibility of electronic records." (Ibid, p14).

These five characteristics of electronic records are regarded by Health Informatics Professionals as important so as to achieve further progress in healthcare. Each of them describes a state of usefulness that could be compromised as a result of technical mediation: these are the possible 'crisis points' of technically-mediated patient information. Presenting patient information can be construed as providing "the correct information at the right time, to the right people"; it is the basis for a strong ethical foundation to eHealth [13]. This is not an easy task given the increasingly complex interactions implied by eHealth. 


\section{Applying an Ethical Framework to a Particular Technology in a Specific Setting: RFID}

Ethical issues may differ depending on various aspects of eHealth - research, policy, deployment or implementation. The ethical issues may also be different according to the specific technology to which they apply. It is therefore important to choose a frame (i.e., framework) or approach to the ethical stance to be taken: a frame that can remain reasonably standard yet can still be applied flexibly according to the particular circumstance under investigation. It is also a priority to maintain a process-related view of ethics, and to search continuously for the kinds of setting in which the ethics of behaviour may be explored and/or debated.

Given contemporary developments in the field of ICT, it is perfectly possible to select numerous examples of technologies that pose ethical challenges. Such technologies affect many fields, and are almost completely ubiquitous. Health services are rapidly expanding their use of ICT, especially to respond to the considerable challenges they face contemporarily. Among these technologies is the very specific field of RFID. Recent articles highlight the privacy and security issues at stake in both the United States and Europe in relation to RFID [1], and with more specific attention to health $[2,17,25]$.

"Radio frequency identification (RFID) is a technology that allows automatic identification and data capture by using radio frequencies" [7]. It can allow "automatic identification of objects, animals or people by incorporating a small electronic chip on its "host". Data is [sic] stored on this chip and can then be "read" by wireless devices, called RFID readers." Such devices can be active, passive, or semi-passive. Today more and more practical industrial products are available that are enlarging RFID's implementation and application, including in the health domain. We take, and understand, RFID to be one of the many eHealth applications currently available on today's market.

The framework we have developed in this paper enables us to pursue further the ethical questions at stake when dealing with eHealth. So too do the three papers presented at the 2007 IFIP summer school that dealt with RFID. We do not, however, explore more widely the various other articles available on this subject (such as $[1,2,17,25]$.

First, we deal with our own approach to the problem domain; then, we expose the thinking of the three separate sets of investigators present at the 2007 summer school.

\subsection{Introducing a Frame}

To examine the ethical issues that might arise from RFID, we consider the fundamentals of the specific technology and its relationship to the 'ethical entity' - which in the case of health is a human being (although it could also be an animal). RFID means that there is a small device that stores data that can be communicated to a receiver for a designated purpose. The device is incorporated on - and even, on occasions in - its host (e.g. a health professional, a product such as a medical device such as a prosthesis, a

${ }^{4}$ See http://ec.europa.eu/information_society/policy/rfid/about_rfid/index_en.htm Accessed 20 September, 2008. 
pharmaceutical product, or a physical piece of clinical or hospital equipment). The ethically challenging characteristics of RFID are that it is a small (possibly unseen) form of ICT that is attached in some way to someone or something which transmits information using a range of radio frequencies. We have said above that it allows "automatic identification and data capture" - identification of what is an ethically pertinent question. It could be simply the device, it could be a person, it could be a condition, or it could be all three.

Relating the use of RFID to the principles of non-malfeasance; beneficence; autonomy; and justice/equity can facilitate ethical decision-making. In any use of RFID that is under consideration in the eHealth domain, the following kinds of questions emerge. Is anyone harmed (most particularly the patient, but we should always consider other people too)? Does the technology promote wellbeing (i.e., does it protect the patient from harm or keep the patient safe)? Does the use of the device promote justice and equity (or, conversely, does it enable discrimination and inequality)? Section 5.2 illustrates some concerns with RFID that may challenge these principles.

\subsection{Outlining Some Empirical Evidence}

Internationally, there is much current interest in the social and ethical considerations that relate to RFID (see e.g., [7,17,25,29]). However, the three groups of researchers whose ideas on RFID on which we rely more substantially are three sets of researchers at the 2007 IFIP summer school; they are listed here in alphabetic order: Hansen \& Meissner [18]; Kumar [23]; and van Lieshout \& Cool [36].

The matter of greatest concern to all three sets of researchers was that of privacy. They raised questions about precisely what aspects of personal privacy may be, at least potentially, contravened by RFID. For example, privacy can be challenged through the particular type of RFID technology that is used, and by the circumstances in which it is used - including the degree of informed consent permitted or rendered possible: such notions of consent can even be provocatively fluid [33]. Privacy (i.e., confidentiality) and consent are key ethical principles in the health domain.

Interesting insights can be drawn with regard to the use of RFID technology from the field of bio-metrics: it can enable foresight into how far the notion of invasive RFID can be stretched (cf. [18]). In terms of the degree of potential exploitation of possibilities that surround RFID, there are a number that raise ethical concerns including: the unauthorised reading of tags; real-time tracking of individuals; the use of data for purposes other than those originally specified; the profiling and monitoring of both people and behaviour (all four of these issues relate to notions of contravention of privacy or confidentiality); and the combining of personal data (which may accelerate or enlarge all of these possible threats/preoccupations). All of the above issues would compromise severely ethical standards of identity management in the health sector.

Two of the three sets of authors [18] and [36] assessed the possible contravention of privacy legislation in Europe as it is based within the European Data Privacy Directive; following the principle of subsidiarity, this legislation is applied with a different range of depth and intensity in the various European Member States. Subsidiarity implies that in European Union law, the Union may only make laws where Member 
States agree that the action of individual countries is not sufficient. Such law, however, needs to be applied by the individual Member States using ways and means that are appropriate to them at their local level.

An in-depth exploration of the legal aspects of eHealth in relation to privacy (but also in respect to certain elements of commercial and liability law) is explored in European Commission [16] and [34]. The policy conclusions of this, latter, 20062007 Legally eHealth study emphasise the need to review legal uncertainties in data protection, product liability, and competition law, to disseminate more adequately legal knowledge and consumer protection issues, and to create eHealth information infrastructure guidelines.

Both articles [18] and [36] acknowledge that potential technological solutions may be introduced as countermeasures to privacy contravention. The latter also identify the role that self-regulation may play as a possible countermeasure to invasion of privacy - on the part of members of both the manufacturing and retailing industry. As a topic, however, this latter area of self-regulation received proportionally less attention and depth of analysis.

In addition to the concept of privacy intervention, [23] covers briefly a range of other possibly unethical uses of RFID. On the one hand, he highlights the separate notions of cyber-racism and/or domination, and the creation of deliberate shifts in people's perception, memory, and identity. On the other hand, he approaches in more detail the possibility that RFID may have various health effects or side-effects.

\section{Conclusions}

Clearly, ethics is important and it matters. Ethics is much more than simply theory; ethics is also about the influence it has on our behaviour and on our day-to-day practice. It is not just about what we as human beings think, it is about what we act out and what we do. Ethical principles can have a huge influence on the policy or political stances and directions that groups and individuals take. A first approach, as a result of this knowledge, is to be informed about what ethical stances and principles are in general. A second is to understand how they apply to specific fields - in this case, eHealth.

The ethics of eHealth may well bring individual welfare into harsh contrast and even conflict with that of the greatest good. We are reminded of the notion that technologies often offer the opportunity to undertake actions and explore possibilities that had previously not been considered - simply because 'we can', whereas we may always consider that there are always things that one should not do [38].

There can also be many tensions, pressures, and contentions between principles and behaviours, and between different interpretations and specific ethical stances. Most ethical questions require more profound thought and deliberation. Ethics is therefore also a process. One of the sponsoring organisations of this series of summer schools, IFIP, has for more than a decade placed considerable emphasis on the creation of fora for dialogue - what it calls 'spaces for discussion' (an argument put forward again in [4]).

While only the single service sector of eHealth (and the role played in it by RFID) was selected for discussion in this paper, the implications for identity and for ethics of various ICT applications warrant further study - especially as technologies converge $[5,35]$. eHealth has, of course, the potential to offer interesting insights, but so do other industrial or service sectors such as eGovernment and eInclusion. 
Our recommendation is to start from the field in which you are, the particular area that concerns you, and to consider the ethical implications of the technology or technologies with which you work.

\section{Acknowledgements}

A certain compatibility may be found between our work and that of Els Soenens [31,32]. Feedback and input from the discussions held with attendees at both the 2007 and the 2008 IFIP summer schools are warmly appreciated. So too are the comments and encouragements of three anonymous 2008 reviewers. The helpful insights of colleagues Chris Zielinski of the World Health Organisation and Marc Griffiths of The Castlegate Consultancy are equally recognised. Final responsibility for the content and orientation of the paper remain with the two authors.

\section{References}

1. Albrecht, K.: How RFID tags could be used to track unsuspecting people. Scientific American (August 2008)

2. Bacheldor, B.: AMA issues ethics code for RFID chip implants. RFID Journal (July 17, 2007)

3. Beauchamp, T., Childress, J.F.: 5th edn. Oxford University Press, Oxford (2001)

4. Berleur, J., Burmeister, O., Duquenoy, P., Gotterbarn, D., Goujon, P., Kaipainen, K., Kimppa, K., Six, B., Weber-Wulff, D., Whitehouse, D. (eds.): Ethics of Computing Committees. Sug-gestions for Functions, Form, and Structure. IFIP-SIG9.2.2. IFIP Framework for Ethics of Computing (September 2008)

5. Bibel, W.: Converging Technologies in the Natural, Social and Cultural World. Special Interest Group for the European Commission via an Expert Group on "Foresighting the New Technology Wave" (2004)

6. COM (2004)356 final e-Health - making healthcare better for European citizens: An action plan for a European e-Health area. European Commission, Luxembourg (30.4.2004)

7. $\operatorname{COM(2007)96~final~Radio~Frequency~Identification~(RFID)~in~Europe.~Steps~towards~a~}$ policy framework (2007)

8. $\operatorname{COM}(2007) 860$ final A lead market initiative for Europe (21.12.2007)

9. $\operatorname{COM}(2008) 414$ final Proposal for a Directive on the application of patients' rights in cross- border healthcare (2.7.2008)

10. $\operatorname{COM}(2008) 489$ final (2008) Telemedicine for the benefit of patients, healthcare systems and society (2.11.2008)

11. $\operatorname{COM(2008)~} 3282$ final (2008) Commission recommendation of 2nd July 2008 on crossborder interoperability of electronic health record systems (2.7.2008)

12. Collste, J.: Applied Ethics and ICT-systems in Healthcare. In: Duquenoy, P., George, G., Kimppa, K. (eds.) Ethical, Legal, and Social Issues in Medical Informatics. Medical Information Science Reference (IGI Global) (2008)

13. Duquenoy, P., George, C., Solomonides, A.: Considering Something ELSE: Ethical, Legal and Socio-Economic Factors in Medical Imaging and Medical Informatics. In: Special Issue: The International Conference MIMI 2007 on 'Medical Imaging and Medical Informatics' August 14-16, 2007, Beijing, China. Müller, H., Gao, X., Luo, S. (Guest Editors) Computer Methods and Programs in Biomedicine 92(3), pp. 227-237. Elsevier Ireland Ltd. (2008), ISSN0169-2607 
14. Eng, T.R.: The eHealth Landscape: A Terrain Mapping of Emerging Information and Communication Technologies in Health and Health Care. The Robert Wood Johnson Foundation (2001)

15. Eysenbach, G.: What is e-health? J. Med Internet Res. 3(2), e20 (2001)

16. European Commission: eHealth priorities and strategies in European countries. Office for Official Publications of the European Communities, Luxembourg (2007)

17. Foster, K.R., Jaeger, J.: The Murky Ethics of Implanted Chips. IEEE Spectrum Online (March 2007)

18. Hansen, M., Meissner, S.: Identification and Tracking of Individuals and Social Net-works using the Electronic Product Code on RFID Tags. In: Fischer-Huebner, S., Duquenoy, P., Zuccato, A., Martucci, L. (eds.) IFIP International Federation for Information Processing. The Future of Identity in the Information Society, vol. 262, pp. 143-150. Springer, Boston (2008)

19. Holm, J.: Review of Beauchamp and Childress (2001). J. Med. Ethics 28, 332 (2002)

20. Joosten, R., Whitehouse, D., Duquenoy, P.: Putting identifiers in the context of eHealth. In: Fischer-Huebner, S., Duquenoy, P., Zuccato, A., Martucci, L. (eds.) IFIP International Federation for Information Processing. The Future of Identity in the Information Society, vol. 262, pp. 389-403. Springer, Boston (2008)

21. Kant, I.: Grounding for the Metaphysics of Morals, translated by James W. Hackett Publishing Company, Ellington (1981)

22. Kluge, E.-H.: A Handbook of Ethics for Health Informatics Professionals. Health Informatics Committee, British Computer Society, London (2003)

23. Kumar, V.: Implantable RFID Chips: Security versus Ethics. In: Fischer-Huebner, S., Duquenoy, P., Zuccato, A., Martucci, L. (eds.) IFIP International Federation for Information Processing. The Future of Identity in the Information Society, vol. 262, pp. 151-157. Springer, Boston (2008)

24. Mordini, E.: Biometrics, Human Body, and Medicine: A Controversial History. In: Duquenoy, P., Carlisle, G., Kimppa, K. (eds.) Ethical, Legal, and Social Issues in Medical Informatics. Medical Information Science Reference (IGI Global) (2008)

25. Michael, M.G., Fusco, S.J., Michael, K.: A Research Note on Ethics in the Emerging Age of UberSurveillance (Überveillance). Computer Communications 31(6), 1192-1199 (2008)

26. Oh, H., Rizo, C., Enkin, M., Jadad, A.: What is eHealth (3): A Systematic Review of Published Definitions. J. Med. Internet Res. 7(1), e1 (2005)

27. Pagliari, C., Sloan, D., Gregor, P., Sullivan, F., Detmer, D., Kahan, J.: What is eHealth (4): A Scoping Exercise to Map the Field. J. Med. Internet Res. 7(1), e9 (2005)

28. Pearsall, J. (ed.): The New Oxford Dictionary of English. Oxford and. Oxford University Press, Oxford (2001)

29. Perakslis, C., Wolk, R.: Social Acceptance of RFID as a Biometric Security Measure. IEEE Technology and Society Magazine (Fall 2006)

30. Purcarea, O., Iakovidis, I., Healy, J.-C.: Access, quality, and economy of eHealth. Unpublished manuscript submitted to the American Journal of Telemedicine (2003)

31. Soenens, E.: Identity management systems in healthcare: the issue of patient identifiers. In: Matyáš, V., et al. (eds.) The Future of Identity in the Information Society. IFIP AICT, vol. 298. Springer, Heidelberg (2009)

32. Soenens, E., Leys, M.: FIDIS deliverable: D4.11 eHealth identity management in several types of welfare states in Europe, 31.3.2008 (2008) 
33. Timmins, N.: Electronic medical records a step closer. Financial Times (2008),

http: / /www.ft.com/cms/s/0/

ff2823e8-85d0-11dd-alac-0000779fd18c.html?nclick_check=1 (accessed January 8, 2009)

34. van Doosselaere, C., Wilson, P., Herveg, J., Silber, D.: eHealth ...but is it legal? Eurohealth 13(2), 1-4 (2007)

35. van Lieshout, M.: Social and Ethical Dimensions of Converging Technologies. Draft proposal for a IFIP-related conference (draft- in preparation) (2008)

36. van Lieshout, M., Cool, L.: Privacy implications of RFID: An assessment of threats and opportunities. In: Fischer-Huebner, S., Duquenoy, P., Zuccato, A., Martucci, L. (eds.) IFIP International Federation for Information Processing. The Future of Identity in the Information Society, vol. 262, pp. 129-141. Springer, Boston (2008)

37. Warwick, K., Cerqui, D.: Prospects for Thought Communication: Brain to Machine and Brain to Brain. In: Duquenoy, P., Carlisle, G., Kimppa, K. (eds.) Ethical, Legal, and Social Issues in Medical Informatics. Medical Information Science Reference (IGI Global) (2008)

38. Weizenbaum, J.: Computer Power and Human Reason: From Judgment to Calculation. W.H. Freeman, San Francisco (1976)

39. Whitehouse, D.: Preface. In: Duquenoy, P., Carlisle, G., Kimppa, K. (eds.) Ethical, Legal, and Social Issues in Medical Informatics. Medical Information Science Reference (IGI Global) (2008a)

40. Whitehouse, D.: The increasing role of eHealth for better specialist care in Europe. In: Building on solid foundations to improve specialist healthcare for European citizens. UEMS 50th anniversary conference, Brussels, April 18, pp. 55-59. UEMS, Brussels (2008b) 